\title{
Holding Onto Your Horses: Conflicts of Interest in Asset Management*
}

\author{
Glenn Boyle \\ Department of Economics and Finance, \\ University of Canterbury, Christchurch, New Zealand \\ Graeme Guthrie \\ School of Economics and Finance, \\ Victoria University of Wellington, Wellington, New Zealand \\ Luke Gorton \\ Independent
}

July 28, 2009

\footnotetext{
* Many people have been helpful to us in the course of this project. At Harness Racing New Zealand, Victor Rolton helped navigate us through the vast amount of information available on the HRNZ website and provided missing data, while Edward Rennell and Maria Morrison were invaluable sources of information about the New Zealand harness racing industry. Chris Bilson, Bruce Grundy, Jayant Kale, Lyndon Moore, Martin Richardson, Phil O'Connor, Tom Smith, Roger Stover and an anonymous referee provided helpful suggestions and comments on earlier drafts of the paper, as did workshop participants at ANU, Melbourne, Otago, Victoria, and the 2006 Asian Finance Association annual conference. Alysia Barnes, Rohan Boyle, Elizabeth Murray, Zheng Hong Zhu and Hanqing Wang all contributed essential research assistance, some of which was funded by Victoria University of Wellington Research Grant 23054. However, none of these is in any way responsible for remaining errors and ambiguities. Most work on this paper was completed while Boyle was employed at the NZ Institute for the Study of Competition and Regulation. None of the views expressed in this paper can be attributed to Harness Racing New Zealand.
} 


\begin{abstract}
Racehorse trainers operate unregulated asset management businesses in which the assets owned by outside clients compete with those owned by trainers for the latter's time, care and attention. However, market mechanisms appear to deal effectively with the resulting agency problem in situations where it matters most. In a sample of 8000 racehorses and their associated stables, we find that client-owned horses do indeed perform worse than their trainer-owned counterparts in small stables that have relatively few outside clients, but that the reverse is true in large stables where client-owners provide much of the trainer's income - agents with more to lose apparently behave better. Moreover, they appear to have good reasons for doing so: client-owned horses that under-perform are more likely to be transferred to another stable, thereby causing a loss of income for the original trainer.
\end{abstract}

\title{
1 Introduction
}

In the standard agency setting, conflicting financial considerations can lead to shirking and/or a transfer of resources from principal to agent. For example, Levitt and Syverson (2008) and Rutherford, Springer, and Yavas (2005) compare house sales in which the real estate agent acts on behalf of a client with sales where the agent is the seller, and find that agent-owned houses sell for approximately $4 \%$ more after controlling for differences in house characteristics. Similarly, Michaely and Womack (1999) compare the stock recommendations of underwriteraffiliated analysts with those of independent analysts and report that the latter are more credible along several dimensions.

However, not all conflicts of interest lead to problems. Gompers and Lerner (1999) find that initial public offerings apparently internalise the conflict of interest between investors and the investment banks that underwrite the securities offerings of firms they own: the latter are initially priced lower but subsequently perform just as well as securities underwritten by independent banks. In a similar fashion, Agrawal and Chen (2008) report that while conflicted analysts do indeed issue more optimistic recommendations, this bias is recognized and appropriately discounted by investors. Moreover, Jackson (2005) notes that opportunistic behavior is, in many situations, constrained by reputational considerations: the desire to obtain repeat business may curtail an agent's incentive to engage in short-term exploitation. Consistent with this view, Ljungvist et al. (2007) find that analyst bias is less pronounced for stocks that are primarily owned by - and hence are most visible to - institutional investors who largely determine analyst reputations. Such findings are important because potential or perceived conflicts of interest often result in calls for government regulation. To the extent that markets are able to self-correct, such intervention is at best unnecessary. 
Houses and stocks are traditional, and relatively conservative, asset classes. In this paper, we examine a potential agency problem that arises in a non-traditional, highly speculative, and unregulated asset class: the conflict of interest between owners and trainers in the horse racing industry. In return for preparing a horse for racing, trainers receive a fixed fee from owners plus a proportion (10\% in the setting we examine) of horse winnings. However, they also train horses on their own account, from which they receive $100 \%$ of winnings. Such an arrangement creates an obvious incentive for trainers to divert effort and overall training quality from horses owned by clients to horses owned by themselves, particularly given the difficulties faced by clients in monitoring and assessing trainer inputs. By comparing the success of horses that are trainer owned with those that are not, we can explicitly identify the difference in performance between an asset manager acting on behalf of a client and the same manager acting on his own behalf.

To undertake this comparison, we hand-collect information on the ownership and performance of approximately 8000 standardbred racehorses and their associated trainers and stables. Despite the incentive for trainers to exploit clients, we find no evidence of a systemic agency problem: on average, client-owned horses perform approximately $12 \%$ better than trainer-owned horses, after controlling for relevant horse and trainer characteristics. Every $\$ 10,000$ earned by the typical horse when trainer owned becomes approximately $\$ 11,220$ when client owned.

What might account for this surprising result? A possible, and appealing, explanation is that the market for horse training services is sufficiently transparent to provide trainers with the right incentives, notwithstanding the difficulties faced by clients in monitoring trainer effort. Each stable relies, to varying degrees, on the continued patronage of outside clients, and so competes with other stables for the custom of these clients. ${ }^{1}$ Because horse training is an experience good, trainers who divert effort towards horses they own themselves risk losing reputation and income as clients become dissatisfied with the performance of their horses and consequently transfer them to other stables. Just as with stock analysts, such future-income concerns may persuade trainers to act in the best interests of clients.

The main results of this paper provide evidence consistent with this view. In stables that have little to lose from upsetting clients - small stables and stables with relatively few outside clients - trainer-owned horses do better on average than client-owned horses, just as the standard agency model would suggest. But the opposite is true in stables where outside clients provide the bulk of a trainer's income. Although the compensation structure for horse trainers encourages the exploitation of clients, trainers who have a lot to lose from upsetting clients apparently choose to put client interests first. Moreover, such behavior appears to be a rational response to the true incentives faced by trainers: under-performing client-owned horses are much more

\footnotetext{
${ }^{1}$ We use the term 'stable' to denote the group of horses prepared by a trainer; that is, the trainer's 'firm'.
} 
likely to be transferred to a different stable, thereby depriving the original trainer of income.

While gambling data from the horse racing industry have been widely used to test hypotheses about market efficiency and investor preferences (Asch, Malkiel and Quandt 1982; Hausch, Lo, and Ziemba 1994; Sauer 1998), the potential value of internal industry data for other research areas has largely gone unrecognized. ${ }^{2}$ These data possess some unique features relevant to analysis of agency problems. First, because horse races take place frequently, there is a wealth of publicly available information. Second, performance is easily measured by horse success. Third, trainer ownership of horses is relatively common, so the potential agency problem occurs on a regular basis.

In the next section, we provide some background information on the specific horse racing industry we examine. Sections 3 and 4 then describe our data and undertake some preliminary comparisons of client- and trainer-owned horses. Sections 5 and 6 provide our principal results: the former isolates the role of the trainer in determining horse performance and examines how this interacts with ownership and stable type, while the latter investigates the link between horse performance and the propensity of client owners to change trainers. Section 7 offers some concluding remarks.

\section{The New Zealand Harness Racing Industry}

Despite there being no shortage of data on horse race outcomes and their associated features, much of this information is not available in a user-friendly form. Fortunately, Harness Racing New Zealand (HRNZ), the governing body of New Zealand (NZ) harness racing, has since 2001 provided website information (www.hrnz.co.nz) on the owners, trainers and performance of every standardbred horse that has raced in NZ since the 1985-86 season, as well as full results for every race that occurred during that period. ${ }^{3}$ This data set is, as far as we know, unique in terms of the rich and detailed information it provides about arrangements in the horse racing industry. ${ }^{4}$ In the next section, we describe this data resource in more detail. This section lays out some basic institutional information about the industry.

The statute that controls NZ racing - The Racing Act — gives responsibility for administration of the racing industry to the NZ Racing Board, which in turn devolves day-to-day control to the governing bodies of the three codes - harness racing (HRNZ), thoroughbred rac-

\footnotetext{
${ }^{2}$ The sole exception seems to be Fernie and Metcalf (1999), who find that English jockeys on incentive contracts generally perform better than those on fixed retainers. However, their sample size is small and they conduct no formal statistical tests.

${ }^{3}$ The NZ racing season runs from 1 August to 31 July.

${ }^{4}$ In principle, similar information could be obtained from the United States Trotting Association (2009), but doing so is considerably more difficult than using the HRNZ site and, moreover, is costly.
} 
ing (NZ Throughbred Racing), and greyhound racing (NZ Greyhound Racing). In the case of HRNZ, one of its most important functions is the licensing of trainers, which requires intending trainers to pass practical and oral tests dealing with the care and preparation of standardbred horses. Having received a license, trainers are subject to the Terms and Conditions of Training mandated by the NZ Harness Racing Trainers and Drivers Association, which outline the rights and obligations of trainers and owners. In particular, these specify that trainers have the right to receive a fixed daily fee from owners (which may vary — primarily on a geographical basis - across trainers) and $10 \%$ of all horse winnings. It also spells out what the fixed fee does and does not cover, and what other costs owners are likely to incur. Thus, the contracts agreed between owners and trainers are essentially homogeneous. ${ }^{5}$

Almost all stables are registered in the name of a single trainer - essentially the stable's chief executive officer. ${ }^{6}$ In small stables, the trainer has direct responsibility for all or most of the hands-on work with stable horses. In large stables, much of this work is necessarily placed in the hands of stablehands (especially when the stable has operations in different parts of the country, as is occasionally the case), but the named trainer is responsible for deciding the allocation of tasks among these employees and hence retains a large degree of control over the quality of a horse's preparation. For example, a trainer can assign a more or less experienced stablehand to the preparation of a particular horse, or he can specify that a given stablehand horse follow a more or less intensive training programme with the horse.

Owners and trainers come together in a variety of ways. In some cases, an owner brings a pre-purchased horse to a trainer; in other cases, the owner arranges assistance from a trainer in buying a horse prior to it entering training; while in still other cases a trainer may seek out owners for purchase of a horse that he believes has potential. In all of these situations, the trainer may or may not become an owner. Finally, some horses are obtained by trainers on their own behalf, for racing in their own or their family's name. One notable feature of the ownertrainer relationship is the almost total absence of written contracts detailing the rights and responsibilities of both parties - most agreements are based on nothing more than a phone call or a handshake. With no formal mechanism for ensuring that trainer performance is satisfactory, continued owner patronage depends primarily on stable reputation. ${ }^{7}$

\footnotetext{
${ }^{5}$ The uniformity of trainer commission rates is itself an interesting phenomenon, although not one we investigate in this paper. For a similar clustering of commission rates in other industries, see Chen and Ritter (2000) and Hsieh and Moretti (2003).

${ }^{6} \mathrm{~A}$ small number of trainers operate in two-person partnerships. However, a trainer cannot simultaneously be in a partnership and run a stable in his own name; in other words, every trainer can be associated with only one stable at a time.

${ }^{7}$ See Banerjee and Duflo (2000) for an illustration of a similar mechanism operating in the Indian software industry.
} 
Having been placed in a stable, whether in the ownership of the trainer, an outside client, or both, a horse is then prepared for racing. Although two- and three-year old horses race mainly against their own age group, most horses are subject to the NZ handicapping system, which attempts to bring together horses of similar ability. For our purposes, this has two principal implications. First, with only a few exceptions, horses move up a class every time they win a race. Thus, success is difficult to maintain for most horses because they eventually "reach their mark". Second, horses must usually qualify — via strong prior performance — for high-stakes races.

Finally, although apparently an industry in decline (Grant 2000; Tolich 2002), the economic impact of NZ horse racing is non-trivial. IER (2004) estimate that this industry produced output worth more than $\$ 1.4$ billion (all figures are in NZ dollars) during 2002-03, approximately 1.2\% of NZ gross domestic product and supporting over 18,000 employees. Henley Centre (2004) reports comparable GDP shares for racing industries in other countries: Australia (0.8\%), Ireland $(0.2 \%)$, United Kingdom (0.3\%), and United States (0.2\%).

The rest of this paper examines whether variation in a trainer's ownership role has any systematic impact on performance, and if so, in what circumstances. Given the $10 \%$ rule noted above, trainers have an obvious incentive to devote more time, effort and general training quality to horses they at least partly own, suggesting that trainer-owned horses should perform better on average.

\section{Data}

Our data set contains details on every horse that competed in NZ harness races during two, arbitrarily-chosen, recent seasons: 1997-98 and 2002-03. Starting with the first race at the first meeting of the 1997-98 season, we record the age, sex, trainer, winnings, and ownership details of the winning horse. Using the HRNZ website, we then track this horse through the rest of the season, recording performance details for each race plus any changes in trainer or ownership. ${ }^{8}$ We repeat this procedure for every other horse in the same race, then move to the second and subsequent races at the same meeting, and so on through all meetings and races held during the 1997-98 season. Finally, we repeat the whole exercise for the 2002-03 season. Because of the relatively short racing life of horses, this gives us two independent samples.

In 1997-98, there were 237 meetings at which 2345 races were contested by 3448 horses who raced a total of 27,451 times; for 2002-03, these figures were 232 meetings, 2350 races, 3263 horses

\footnotetext{
${ }^{8}$ Because the precise dates of changes in ownership or stable were often difficult to identify from the website, we subsequently obtained this information directly from HRNZ. We are grateful to Victor Rolton for assisting us with this.
} 


\section{Table 1: Horse Descriptive Statistics}

This table provides summary information about the horses in our dataset. Trainer-owned horses are those where the trainer has at least a partial ownership share. Race starts is the number of races in which the horse competes during the season. Maximum season earnings is equal to total possible stake winnings if all races are won. Ownership group size is the number of individuals who share ownership of the horse. Stable size is the number of horses per stable. Horses that change stables or switch between client- and trainer-ownership during a season are treated as separate observations.

\begin{tabular}{|c|c|c|c|c|c|c|c|c|c|c|}
\hline \multirow[b]{2}{*}{ Characteristic } & \multicolumn{5}{|c|}{$\begin{array}{c}1997-1998 \\
(n=4087, \text { of which } 59 \% \text { are male } \\
\text { and } 39 \% \text { are trainer-owned })\end{array}$} & \multicolumn{5}{|c|}{$\begin{array}{l}2002-2003 \\
(n=3861, \text { of which } 58 \% \text { are male } \\
\text { and } 36 \% \text { are trainer-owned })\end{array}$} \\
\hline & Mean & Std dev & Median & Min & Max & Mean & Std dev & Median & Min & $\operatorname{Max}$ \\
\hline Age (years) & 4.6 & 1.6 & 4 & 2 & 11 & 4.4 & 1.5 & 4 & 2 & 13 \\
\hline Race starts & 6.7 & 5.8 & 5 & 1 & 43 & 7.0 & 5.8 & 5 & 1 & 45 \\
\hline Season earnings $(\$ 1000)$ & 4.2 & 12.6 & 0.7 & 0 & 302.5 & 5.0 & 14.3 & 1.3 & 0 & 396.7 \\
\hline Max. season earnings $(\$ 1000)$ & 30.1 & 46.3 & 15.8 & 0.6 & 671.9 & 36.2 & 58.4 & 18.8 & 1.1 & 896.0 \\
\hline Ownership group size & 2.6 & 2.2 & 2 & 1 & 10 & 2.7 & 2.3 & 2 & 1 & 10 \\
\hline Stable size & 4.5 & 6.1 & 2.0 & 1 & 59 & 4.53 & 6.7 & 2.0 & 1 & 66 \\
\hline
\end{tabular}

and 27,126 horse-races. Some horses changed trainers during the season, or switched between client- and trainer-ownership. Each such change was treated as a different horse, leading to a final dataset of 4087 horses in 1997-98 and 3861 in 2002-03. The respective trainer numbers are 984 and 852 .

Table 1 provides some summary statistics for the horses in our sample. In both seasons, the median horse is a four year old male that competes in five races, and earns approximately $\$ 1000$ (out of a possible $\$ 16,000-\$ 18,000)$ for its two owners. However, some of these characteristics vary considerably across horses, with standard deviations as large or larger than their corresponding means and medians.

Our primary interest is in the relationship between horse performance and whether or not it races in the interest of its trainer. Although we know the identity of each horse's owners, their specific ownership shares are not publicly available. Thus, we distinguish only between horses in which the trainer has some ownership share (henceforth trainer-owned) and those that are completely client-owned. This simple categorization is not solely a data-induced necessity. By defining as trainer-owned any horse in which the trainer simply has a non-zero ownership interest, we guard against the possibility, to be discussed in more detail later, that trainer horseownership is constrained by affordability issues. In our sample, $39 \%$ of horses are trainer-owned during the 1997-98 season and 36\% during the 2002-03 season.

Two simple measures of performance are (i) total season earnings and, for those accustomed 
to thinking in terms of returns, (ii) total season earnings divided by beginning-of-season horse value (the opportunity cost of horse ownership). Unfortunately, the former is of doubtful validity for our purposes. Because total earnings are largely determined by horse eligibility to compete in high stakes races, which for many horses primarily reflects their performance in previous seasons, a horse could perform poorly in the current season but nevertheless earn more than a consistently-performing horse simply because its efforts in previous seasons qualified it for higher-stakes races (which may have occurred in a different stable under different ownership). Scaling total earnings by the cost of investment would in principle resolve this problem, as true horse value would take into account potential earnings during the forthcoming season, but it encounters the practical difficulty that there is no liquid, and quoted, secondary market for racehorses, so this variable is unobservable. An alternative would be to use the price initially paid for the horse by its owners as a proxy for its beginning-of-season value, but this too has significant problems. First, some horses are retained by their breeders and so no such price exists, while many other horses are sold privately and the price is not publicly revealed. Second, where a price does exist, it may be several years old and hence contain little information about the horse's current value. Third, even when a price exists and is current, Wilson and Rambaut (2008) note that this - particularly for a female horse - often reflects its potential breeding value just as much as its likely racing ability, so a horse that has low expected racetrack value may sell for more than a horse that seems likely to perform well.

To get around this problem, we instead use two performance measures that attempt to capture the extent to which a horse races to its potential. The first, commonly used in the industry itself to measure the performance of trainers and drivers, measures the regularity with which the horse finishes in a position that pays a significant stake to owners:

$$
\text { consistency ratio }=\frac{9 \times \text { number of firsts }+5 \times \text { number of seconds }+3 \times \text { number of thirds }}{9 \times \text { number of races during season }} \text {. }
$$

The 'rewards' (9, 5 and 3$)$ to finishing first, second and third respectively represent a longstanding industry convention about the relative merits of these placings. ${ }^{9}$ The second measures the extent to which a horse achieves its maximum-possible earnings:

$$
\text { earnings ratio }=\frac{\text { stake earnings during the season }}{\text { sum of winning stakes from all races entered during the season }} .
$$

The two performance measures are quite highly correlated, but the latter gives more weight to high-stakes races. This feature recognises that trainers may use their experience and knowledge

\footnotetext{
${ }^{9}$ This view is based on some 1948 work by two New York teachers named Haswell and Mead, whose analysis of past results determined that a win is $80 \%$ better than running second and three times as good as finishing third. Unfortunately, this work does not seem to have ever been published, and its details remain a mystery even to industry participants. For more information, see Siegel (2002, 52), Ainslie (1970, 243-244), and Michigan Harness (2001).
} 
Table 2: Horse Ownership and Performance: Comparison of Means and Medians

The sample of horses is the same as in Table 1. The first two columns of numbers report performance statistics for, respectively, horses in which the trainer has an ownership stake and those in which he does not. The third column reports the difference and associated significance level ( ${ }^{* * *}$ denotes significance at the $1 \%$ level). The test for differences in means is based on a $z$-statistic, while that for differences in medians is based on the Mann-Whitney $U$-statistic. Consistency ratio is a weighted average estimate of a horse's propensity to be among the first three placegetters. Earnings ratio is total earnings divided by maximum-possible earnings.

\begin{tabular}{|c|c|c|c|c|c|c|}
\hline \multirow[b]{2}{*}{ Variable } & \multicolumn{3}{|c|}{$\begin{array}{l}1997-1998 \\
(n=4087)\end{array}$} & \multicolumn{3}{|c|}{$\begin{array}{l}2002-2003 \\
(n=3861)\end{array}$} \\
\hline & Trainer-owned & Client-owned & Difference & Trainer-owned & Client-owned & Difference \\
\hline \multicolumn{7}{|c|}{ Consistency ratio } \\
\hline Mean & 0.117 & 0.146 & $-0.029^{* * *}$ & 0.120 & 0.162 & $-0.042^{* * *}$ \\
\hline Median & 0.039 & 0.079 & $-0.040^{* * *}$ & 0.056 & 0.105 & $-0.049^{* * *}$ \\
\hline \multicolumn{7}{|c|}{ Earnings ratio } \\
\hline Mean & 0.089 & 0.108 & $-0.019^{* * *}$ & 0.095 & 0.126 & $-0.032^{* * *}$ \\
\hline Median & 0.031 & 0.049 & $-0.018^{* * *}$ & 0.044 & 0.069 & $-0.025^{* * *}$ \\
\hline
\end{tabular}

to prepare a horse for the big occasion by racing its way to fitness in lesser races. If this strategy is successful, the horse's consistency ratio would be low, but its earnings ratio would be high. ${ }^{10}$

Table 2 reports the mean and median values of these two performance measures for both client-owned and trainer-owned horses. Surprisingly, client-owned horses perform significantly better than trainer-owned horses on average: the median client-owned horse is $79 \%-102 \%$ more consistent and almost $60 \%$ better at realising potential winnings than its trainer-owned counterpart. ${ }^{11}$ Despite trainers having a strong incentive to devote more time and effort to horses they own themselves, these results are not suggestive of an agency problem: horses owned by outside clients do not just perform as well as trainer-owned horses, they actually perform much better.

Of course, other variables that potentially affect horse performance, such as horse and trainer quality, may also be correlated with horse ownership in our sample. In the next section, we attempt to deal with such issues by estimating multiple regression models that include various

\footnotetext{
${ }^{10}$ These performance measures could be misleading if trainers were able to play 'games' in their own interests by entering client-owned horses in low-stakes races where the competition is weak while simultaneously entering their own in high-stakes events against strong competition. All else equal, client-owned horses would then perform better according to our measures, and we might wrongly conclude that there is no agency problem. However, the ability of trainers to act in this way is severely constrained by the handicapping system discussed in Section 2: successful horses cannot race perpetually in low-grade events, and entry in high-stakes races requires prior qualification.

${ }^{11}$ Mean differences are smaller, but still noteworthy: client-owned horses are $25 \%-35 \%$ more consistent and $21 \%-33 \%$ better at realising their potential winnings.
} 
control variables.

\section{Is there an agency problem?}

We first estimate regression models of the general form

$$
\text { horse performance }=\alpha_{0}+\alpha_{1}(\text { client owner })+\sum_{i} \beta_{i}\left(\operatorname{control}_{i}\right)+\varepsilon,
$$

where 'client owner' equals 1 if the trainer is not one of the horse's owners and 0 otherwise, and each ' control $_{i}$ ' is a variable that potentially influences horse performance over the course of a season. The latter has two principal determinants: the racetrack ability of the horse, and the quality of its preparation and training. Regardless of ownership, fast horses will, all else equal, be more successful than those with less speed, while horses under the care of superior and more highly motivated trainers will tend to perform better than those domiciled in weaker stables. ${ }^{12}$

Racehorse quality depends on a myriad of factors, including breeding, size, conformation, heart score, temperament, tractability, and so on, but most of these are unobservable or difficult to quantify in a form useful for empirical analysis. Instead, we use three underlying indicators of a horse's likely racetrack success during a given season: age, sex, and natural ability. Horse speed and stamina typically decline beyond four-five years of age, so we expect our performance measures to be inversely related to age. ${ }^{13}$ Also, male horses are generally more robust than females, which is likely to result in better performance on average. We therefore employ an indicator variable that is equal to 1 if the horse is male and 0 otherwise. ${ }^{14}$

Even allowing for differences in age and sex, some horses simply have greater ability than others and thus will perform better on average. Unfortunately, natural horse ability is not directly observable. An obvious proxy is some measure of historical performance, such as the previous season's earnings. However, this would be equal to zero for many horses in our sample, due to their not having raced in a prior season, and so would fail to distinguish between many horses of different ability. Instead, we exploit the fact that those with the best knowledge about a horse's ability are those closest to it - its trainer and owners. If they believe the horse to be of high ability, they will seek to enter it in high-quality races offering high stakes. If, on

\footnotetext{
${ }^{12}$ Because we focus on season performance, we can ignore race-specific determinants of performance such as barrier draw, track conditions, race distance, and quality of the assigned raceday driver. However, we implicitly consider the importance of these variables in unreported analysis that restricts our sample to horses that race at least five times during the season. This has little effect on the results.

${ }^{13}$ Although young horses (two and three year-olds) lack experience, which could be expected to worsen performance, they primarily race only against each other.

${ }^{14}$ Biological studies of racehorse performance (Gaffney and Cunningham 1988; Wilson and Rambaut 2008) reveal systematic differences between male and female horses.
} 
the other hand, they consider it to be of more modest ability, they are more likely to restrict it to low-stakes races where it has a greater chance of paying its way. To capture this 'insider knowledge' about horse ability, we calculate the horse's maximum-possible season earnings (that is, the amount of money it would have earned if it had won all its races) as a proxy for beginningof-season expectations by insiders about future horse performance. The greater this amount, the higher the confidence of the horse's principal connections about its ability. ${ }^{15}$

Horses of identical ability may perform differently because of differences in the quality of their training; all else equal, better training will result in better performance. We control for this in two ways. First, we use average annual stake earnings of the trainer's stable during the previous five seasons as a proxy for generic trainer quality. Second, as trainers acquire greater professional visibility and peer recognition by winning high-prestige races, they are likely to attach particular importance to horses that can potentially compete in such races. This suggests that, regardless of ownership, the best horses in each stable will receive a disproportionate share of the trainer's care and attention, and hence perform better. We attempt to capture this effect by calculating the ratio of a horse's maximum possible earnings to the average of maximum possible earnings across all horses in the same stable: because high-prestige races typically carry greater stakes, high values of this ratio will be associated with horses that tend to compete in high-prestige events (relative to those contested by the rest of the stable), and hence make the greatest potential contribution to their trainer's professional reputation. ${ }^{16}$

In these regression models, the client-owner coefficient estimates the average performance superiority of client-owned horses. This implicitly assumes that the allocation of owners to horses is exogenous, but two phenomena (that work in opposite directions) make this unlikely. First, trainers generally have more information and knowledge about horse quality and ability than clients, and so can be expected to use this advantage to purchase ownership only in the horses most likely to succeed. Second, wealthy outside owners who face weaker financial constraints than trainers may disproportionately purchase the highest-quality horses that subsequently perform best. The first of these implies that trainer-owned horses should perform better regardless of any agency-induced differential effort; the second implies the opposite. To the extent that one or other of these dominates, and is not captured by our proxies for horse ability, any performance difference between client- and trainer-owned horses may simply reflect the endogenous determination of ownership, rather than trainers' responses to the conflict of interest inherent

\footnotetext{
${ }^{15}$ Scaling this variable by the number of races the horse has during the season yields very similar results.

${ }^{16}$ If, regardless of race prestige or ownership status, trainers are directly motivated by potential stake earnings, then the ratio of horse maximum possible earnings to the sum of maximum possible earnings across all horses in the same stable is also likely to be important. In unreported regressions, we also experiment with this variable, but it generally has little explanatory power and leaves our other results unaffected.
} 
in their remuneration structure. ${ }^{17}$

Two features of our study help control for the second of these problems. First, we define a trainer-owned horse as one in which the trainer has some ownership share: although trainers may indeed face greater financial constraints than clients in owning $100 \%$ of a horse, this need not preclude them from owning some portion. Second, client owners possessing a valuable horse are unlikely to entrust its care to a poor trainer, so the trainer quality variable provides an indirect control for any biases created by greater client wealth. Thus, the net effect of endogeneity issues should be to bias our results towards finding a performance advantage for trainer-owned horses and hence concluding that the owner-trainer relationship is characterized by an agency conflict.

Another possible problem with our regression model is that in the specifications where the dependent variable is the earnings ratio, maximum-possible earnings appears on both sides of the equation, creating the potential for a spurious negative relationship between our performance and horse ability variables. However, this does not seem to be a major issue here. First, as we shall see, the estimated relationship between performance and ability is strongly positive, so the behavioral link between these two variables appears to dominate the mechanical. Second, the problem does not arise when the consistency ratio is the dependent variable and, again as we shall see, the two performance measures yield similar results.

Table 3 presents regression results for both seasons, both performance measures, and two model specifications. Despite the possibility that endogenous horse ownership choices are, as discussed above, likely to bias our results towards finding a performance advantage for trainerowned horses, client-owned horses perform significantly better on average. In columns (1) and (3) of each panel, we control for horse age and sex, which lowers the estimated impact of outside ownership compared with the simple mean differences reported in Table 2. For example, the average improvement in the consistency ratio for horses with no trainer ownership in 1997-98 is now 0.023, compared with 0.029 in Table 2. Nevertheless, these differences remain significant at the $1 \%$ level or better. In columns (2) and (4) of each panel, we add the additional control variables. This has a more substantial effect on the impact of outside ownership, but all the ownership coefficients remain statistically significant and economically meaningful.

Some simple calculations illustrate the quantitative impact of client ownership. For example, evaluating column (2) of panel B at sample average values, the typical horse in the 199798 sample has a predicted earnings ratio of 0.094 if trainer owned and 0.104 if client owned. Using column (4) of the same panel, the corresponding figures for 2002-03 are 0.109 and 0.124 respectively. Over both seasons, the predicted earnings ratio is about $12 \%$ greater if client

\footnotetext{
${ }^{17}$ In the case of trainer informational advantages, there may, of course, still be an agency problem, but one with adverse selection, rather than moral hazard, origins.
} 


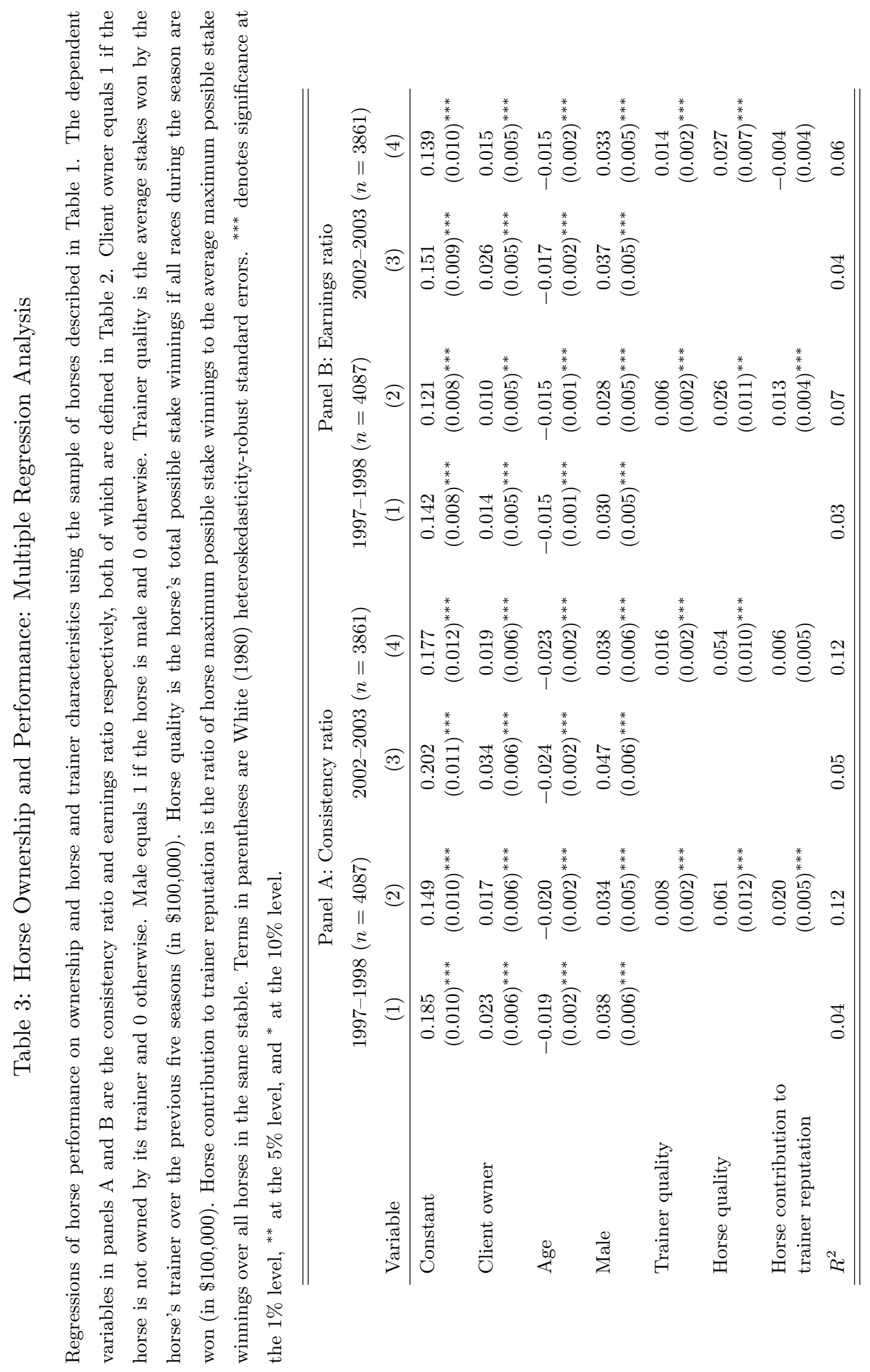


owned. Put another way, for every $\$ 10,000$ earned by the typical horse when trainer owned, it wins approximately $\$ 11,220$ when client owned.

Although the control variables are not our primary focus, it is comforting to know that their coefficients seem sensible. In all specifications, horses that are male, score highly on our proxy for intrinsic ability, and are prepared by high-quality trainers do better, while older horses do worse. Client ownership has roughly the same average impact on horse performance as a year less of age, an extra $\$ 100,000$ per season of historical trainer success, or an extra $\$ 30,000$ in maximum-possible earnings. The marginal impact of client ownership is approximately half that of being male.

Overall, the results in Table 3 reject the simple agency model. Even after controlling for characteristics such as age, sex, and horse and trainer quality, client-owned horses on average out-perform trainer-owned horses by an economically significant amount, despite trainers having the incentive and opportunity to favor their own horses.

\section{Resolving the agency problem: stable dependence on income from client-owners}

The analysis in Section 4 documents a positive relationship between client ownership and horse performance. It is tempting to conclude that, notwithstanding the difficulties faced by owners in observing and monitoring trainer effort, the market for horse training services is sufficiently transparent to provide trainers with the right incentives: future income concerns, as in the models of Jackson (2005) and Puri (1999), motivate trainers to treat clients well. But such a conclusion would be premature. Perhaps the relationship is spurious due to the ownership variable being correlated with some unknown determinant of horse performance; for example, if client owners tend to place their horses with trainers of proven ability, then the superior performance of client-owned horses may primarily reflect their receiving training services that are 'better' along some dimensions not picked up by our trainer quality variable. Or perhaps client owners monitor their horse's preparation more closely if the trainer is not also an owner.

To address these issues, we extend the above analysis in two ways. First, we attempt to isolate the training effect by examining the 'within-stable' relationship between horse performance and trainer ownership. That is, we construct trainer-owned and client-owned 'horse portfolios' for each stable, and then calculate and compare the performance of each portfolio. Forming stablebased portfolios in this way effectively neutralizes trainer quality effects, since superior training ability should, other motivations the same, improve the performance of both client- and trainerowned horses equally, leaving the difference unchanged. 
Second, using these stable portfolios, we examine the cross-sectional variation in the performance differential between client-and trainer-owned horses. If the results of Section 4 do indeed indicate desirable incentives at work, then the performance differential should systematically vary with the importance of outside clients to a trainer's income. Trainers who allocate greater effort to horses they own themselves risk alienating clients who, dissatisfied with the performance of their horses, then transfer them to other stables, thereby depriving the trainer of income. In practice, however, the strength of this incentive varies across stables. Trainers earn income in a variety of ways: not only from providing training services, but also from buying and selling horses, from racing-related activities (for example, farrier work, or education of young horses), and from activities unrelated to racing (such as farming). Clearly, a trainer for whom training activities are little more than a part-time hobby has little reliance, if any, on his ability to attract and retain outside clients, since the failure to do so will have few financial consequences. By contrast, trainers who are dependent on training activities for the bulk of their income will be more concerned about maintaining a healthy supply of clients. ${ }^{18}$ In short, the performance advantage of client-owned horses should be strongest in stables that have the most to lose from exploiting their clients.

We use two measures to capture the strength of a stable's incentives to satisfy outside clients. First, stable size, as measured by the number of horses raced by the stable during the season. ${ }^{19}$ Trainers with large stables are presumably most dependent for their income on the provision of training services, and hence are highly motivated to keep clients happy. Moreover, large stables are able to generate economies of scale, and so will wish to protect the ensuing rent. By contrast, a trainer who runs a small stable and derives the majority of his income from non-training sources has less to lose from putting his own interests first. Second, the ownership ratio, as measured by the number of client-owned horses raced by the stable during the season divided by the number of trainer-owned horses. As well as being a more direct measure of the relative importance of client-owned horses to a stable, this variable allows us to distinguish between small stables that are small due to the bulk of the trainer's livelihood coming from elsewhere (and hence having weak incentives to treat clients correctly), and small stables that are small due to the trainer being relatively new to a training career (and therefore wishing to establish a good reputation). Because the latter are likely to be more financially constrained,

\footnotetext{
${ }^{18}$ This idea also has antecedents in the theoretical models of Williams (1998), Telser (1980), Klein and Leffer (1981), and Fama (1980). Although the specific mechanisms underlying these models differ somewhat, they share a common implicit theme: that the need to compete for clients can lessen the problems arising from conflicts of interest.

${ }^{19}$ Analogously, Ljungqvist et al. (2007) use the magnitude of underwriting business as a proxy for investment bank reputation capital.
} 
they will tend to own few horses themselves and hence have a high proportion of client-owned horses among the small number of horses they prepare.

To determine whether the difference in performance between client- and trainer-owned horses varies with the importance of the former to a stable's total income, we regress the within-stable difference in portfolio performance on our two measures of client importance. For this exercise, we combine our two seasons of data and exclude those stables that do not contain at least one client-owned horse and one trainer-owned horse over the course of those two seasons; this leaves a total of 572 different stables in our sample. For each stable, we compute and record the characteristics (performance, age, sex, maximum earnings and ownership) of the group of horses owned by the trainer and, separately, those owned by clients. Because this procedure involves combining data from two seasons, we also convert 2002-03 earnings to 1997-8 dollars using the relevant change in the NZ Consumer Price Index when calculating the earnings ratio performance measure for each group. ${ }^{20}$ We compute the performance advantage of the client-owned group as:

$$
\begin{aligned}
\text { performance premium }= & \text { performance of stable's client-owned horses } \\
& \quad-\text { performance of stable's trainer-owned horses }
\end{aligned}
$$

for both the consistency and earnings ratio measures of performance. We regress these performance premia on one of our two measures of stable client-importance, and on the following control variables: (i) the average age of the stable's client-owned horses minus the average age of its trainer-owned horses, (ii) the proportion of males among the stable's client-owned horses minus the proportion of males among its trainer-owned horses, and (iii) the average maximumpossible stake earnings of the stable's client-owned horses minus the average maximum-possible stake earnings of its trainer-owned horses (with 2002-03 earnings adjusted for inflation). In all specifications, we use the natural log of our client importance variables, since any effect of these on trainer incentives is likely to diminish beyond a certain point.

Table 4 contains summary statistics for these variables. In the average stable, there is little age or sex difference between client- and trainer-owned horses, but the latter race for greater stakes (consistent with trainers having better information about horse potential). And, in contrast to the previous horse-focused analysis, mean performance at the stable level is better among trainer-owned horses, although the earnings ratio difference is statistically significant only at the $10 \%$ level. Grouping the horses into stable portfolios effectively reduces the statistical weight allocated to horses that are trained in large stables; the weaker performance advantage

\footnotetext{
${ }^{20}$ In practice, this adjustment makes little difference to the results as the average inflation rate during this period was less than $2 \%$ per annum.
} 
Table 4: Stable Descriptive Statistics

This table provides summary information about the stables in our two-season sample. A total of 572 different trainers prepare both client-owned and trainer-owned horses over the two seasons. Consistency (Earnings) Ratio Premium equals the consistency (earnings) ratio for the stable's portfolio of client-owned horses minus the consistency (earnings) ratio for the stable's portfolio of trainer-owned horses. Age difference is the average age of the stable's client-owned horses minus the average age of its trainer-owned horses. Male difference is the proportion of males among the stable's clientowned horses minus the proportion of males among its trainer-owned horses. Quality difference is the average maximum-possible stake earnings of the stable's client-owned horses minus the average maximum-possible stake earnings of its trainer-owned horses. 2002-03 dollar values are converted to 1997-98 dollars using the NZ Consumer Price Index. In the first five rows, ${ }^{* * *}$ denotes that the mean value differs from zero at the $1 \%$ significance level, ${ }^{* *}$ at the $5 \%$ level, and ${ }^{*}$ at the $10 \%$ level. In the last two rows, Stable size is the number of horses raced by the stable during the two seasons covered by our sample, while Ownership ratio is the number of horses in the stable's client-owned portfolio divided by the number in its trainer-owned portfolio.

\begin{tabular}{lccccc}
\hline \hline Variable & Mean & Std dev & Median & Min & Max \\
\hline Consistency ratio premium & $-0.012^{* *}$ & 0.14 & 0.000 & -0.80 & 0.56 \\
Earnings ratio premium & $-0.008^{*}$ & 0.11 & -0.001 & -0.80 & 0.42 \\
Age difference & 0.032 & 1.43 & 0.000 & -6.00 & 6.00 \\
Male difference & $-0.035^{*}$ & 0.47 & 0.000 & -1.00 & 1.00 \\
Quality difference $(\$ 100,000)$ & $-0.050^{* * *}$ & 0.33 & -0.023 & -3.20 & 1.20 \\
Stable size & 10.80 & 12.8 & 6.000 & 2 & 115 \\
Ownership ratio & 3.205 & 6.016 & 1.000 & 0.091 & 68 \\
\hline \hline
\end{tabular}

of client-owned horses in this stable-based analysis therefore provides tacit support for the view that large stables face sharper incentives in dealing with clients.

Table 5 explores this idea in more detail by splitting our sample of 572 trainers into two groups - those above and below the sample medians for, successively, stable size and ownership ratio - and then calculating the mean performance premium for each group. In general, stables that are relatively large, or that contain a relatively high proportion of client-owned horses, tend to see their client-owned horses perform slightly better than their trainer-owned counterparts, although the difference is statistically insignificant. By contrast, relatively small stables, and stables with a relatively low proportion of client-owned horses, are associated with trainer-owned horses having a significant performance edge of between 1.5 and 3 percentage points.

Table 6 confirms that these results are unaffected by including the control variables in the regressions described above. The more a stable has to lose from upsetting clients, the bigger the performance advantage of the client-owned group of horses, with this effect being both statistically (at the $5 \%$ level or better) and economically significant. For example, holding all 
Table 5: Stable Performance, Ownership, and the Importance of Outside Clients: Comparison of Means

This table reports the mean difference in performance between a stable's portfolio of client-owned horses and its portfolio of trainer-owned horses, conditioned on whether the stable is above or below the sample median for our two measures of outside-client dependence. All variables are defined in Table 4. ${ }^{* * *}$ denotes different from zero at the $1 \%$ significance level, ${ }^{* *}$ at the $5 \%$ level, and ${ }^{*}$ at the $10 \%$ level.

\begin{tabular}{lcc}
\hline \hline & Consistency ratio premium & Earnings ratio premium \\
\hline Stable size > sample median & -0.001 & 0.001 \\
Stable size $\leq$ sample median & $-0.022^{* * *}$ & $-0.015^{* *}$ \\
Difference & $-0.021^{*}$ & $-0.017^{*}$ \\
Ownership ratio $>$ sample median & 0.006 & 0.007 \\
Ownership ratio $\leq$ sample median & $-0.029^{* * *}$ & $-0.020^{* * *}$ \\
Difference & $-0.035^{* * *}$ & $-0.027^{* * *}$ \\
\hline \hline
\end{tabular}

else equal, doubling either of the underlying stable size or ownership ratio variables raises the average performance premia by $0.008-0.011$ points, amounts approximately equal (in absolute value) to their respective sample means. ${ }^{21}$ Setting other variables equal to their sample means, moving from the 10th to the 90th percentile of the stable size variable raises the predicted consistency ratio difference between the client- and trainer-owned horses from -0.030 to 0.005 , and the predicted earnings ratio difference from -0.023 to 0.008. Similarly, moving from the 10th to the 90th percentile of the ownership ratio variable raises the predicted consistency ratio premium from -0.034 to 0.013 , and the predicted earnings ratio premium from -0.026 to 0.013 .

A stable's dependence on outside clients thus appears to be an important determinant of relative performance: client-owned horses perform significantly worse than trainer-owned horses in stables that receive little of their income from outside clients, but the reverse is true in stables where these clients are more prominent. Agents with a lot to lose apparently behave much better.

\section{Are trainers really subject to client-imposed discipline?}

We have suggested that the results of Section 5 can be seen as evidence of racehorse trainers responding rationally to financial incentives. But this implicitly assumes that client-owners impose discipline on trainers by 'sacking' them (that is, by transferring their horses to other

\footnotetext{
${ }^{21}$ When a variable doubles in size, its natural $\log$ value increases by $\log 2$, so the effect on the performance premia of doubling stable size or ownership ratio equals the product of their respective Table 6 coefficients and $\log 2$.
} 
Table 6: Stable Performance, Ownership, and the Importance of Outside Clients: Regression Analysis

This table estimates the impact that ex-ante measures of the importance of outside clients to a stable have on the performance-ownership relationship. In all regressions, the sample size is 572 , and the dependent variable is the difference between the performance measure for the stable's portfolio of client-owned horses and the same performance measure for its portfolio of trainer-owned horses. All variables are defined in Table 4. Terms in parentheses are White (1980) heteroskedasticity-robust standard errors. $^{* * *},{ }^{* *}$ and ${ }^{*}$ denote significance at the $1 \%, 5 \%$ and $10 \%$ level respectively.

\begin{tabular}{lcccc}
\hline \hline & \multicolumn{4}{c}{ Dependent variable } \\
& Consistency ratio premium & Earnings ratio premium \\
\hline Constant & $-0.029^{*}$ & -0.007 & $-0.026^{* *}$ & -0.006 \\
& $(0.016)$ & $(0.006)$ & $(0.013)$ & $(0.005)$ \\
Age difference & $-0.022^{* * *}$ & $-0.022^{* * *}$ & $-0.014^{* * *}$ & $-0.014^{* * *}$ \\
& $(0.005)$ & $(0.005)$ & $(0.003)$ & $(0.003)$ \\
Male difference & $0.035^{* * *}$ & $0.035^{* * *}$ & $0.024^{* *}$ & $0.025^{* *}$ \\
& $(0.013)$ & $(0.013)$ & $(0.010)$ & $(0.010)$ \\
Quality difference & $0.143^{* * *}$ & $0.143^{* * *}$ & $0.079^{* * *}$ & $0.079^{* * *}$ \\
$(\$ 100,000)$ & $(0.021)$ & $(0.029)$ & $(0.020)$ & $(0.019)$ \\
$\log ($ Stable size $)$ & $0.014^{* *}$ & & $0.012^{* *}$ & \\
& $(0.007)$ & & $(0.005)$ & \\
$\log ($ Ownership ratio $)$ & & $0.016^{* * *}$ & & $0.013^{* * *}$ \\
$R^{2}$ & & $(0.005)$ & & $(0.003)$ \\
\hline \hline
\end{tabular}

stables) for perceived under-performance. If the diversion of effort to their own horses has no adverse consequences for trainers, then it would be difficult to maintain the view that our earlier results reflect trainer concerns about their future income. Instead, if our incentives-based story has substance, then the threat of sacking must be a real one for trainers.

To examine this issue, we again combine the two seasons of data and analyze the sub-sample of 4000 horses that (i) were client-owned and (ii) remained in the same ownership throughout their respective seasons. Of these, 354 changed stables during the course of a season (that is, the original trainer was replaced), suggesting that a trainer's probability of being sacked is only $8.85 \%$. However, this almost certainly underestimates the true probability, possibly severely: for example, because our data only identify stable changes once a horse has raced from its new stable, horses that transfer stables but then do not race again until the following season are erroneously counted among the 3646 horses that were not associated with a trainer sacking. Despite this problem, trainer replacement appears to be strongly associated with horse underperformance - panel A of Table 7 reveals that horses which change stables perform (prior to the change) significantly worse on average than those that remain in the same stable throughout the season. 
Moreover, this difference is quite substantial: the latter group's mean consistency ratio is $73 \%$ higher, and its mean earnings ratio $71 \%$ higher, than that of the group that changes stables.

To explore this issue more deeply, we investigate the relationship between horse performance and the probability of trainer replacement. Because the relevant measure of performance - from the perspective of client-owners' relationships with trainers - seems likely to be performance relative to expectations, we proceed in three steps. First, in our sub-sample of 4000 horses, we regress horse performance on the control variables appearing in Table 3 (after converting 200203 monetary values to 1997-98 dollars). Second, we calculate the residuals from this regression as a measure of unanticipated horse performance. Third, we create a new variable set equal to 1 if the horse changes stables during the season and 0 otherwise, and then regress this (using maximum-likelihood logit) on unanticipated performance. The results of this third step appear in panel $\mathrm{B}$ of Table 7 and reveal strongly positive (at the $1 \%$ significance level) relationships between the probability of sacking and both measures of horse underperformance. ${ }^{22}$ The most under-performing horses are almost twice as likely to change stables as those with the strongest performance: those in the bottom performance residual decile have an estimated probability of trainer replacement of approximately $11 \%$ while the corresponding figure for those in the top decile is only $6 \% .^{23}$

Together, panels $\mathrm{A}$ and $\mathrm{B}$ of Table 7 suggest that outside owners react to horse underperformance, and therefore that trainers run the risk of adverse future-income consequences if they divert effort from client-owned horses to horses they own themselves. However, one possible problem with this interpretation is that some horses may change stables not because the owner sacks the trainer, but rather because the trainer sacks the horse. To the extent the latter situation occurs (and recall that doing so is costly to the trainer due to the loss of daily fee income), the results in panels $\mathrm{A}$ and $\mathrm{B}$ may indicate only that trainers are more likely to sack underperforming horses. Unfortunately, our data contain no information on the reasons for stable changes, but an indirect way of inferring whether or not this is a problem for our analysis is to compare the performance of horses that change stables before and after the change. If stable changes are primarily due to dissatisfied owners sacking the original trainer (and issuing the new trainer with appropriate instructions), then we would expect at least some horses to per-

\footnotetext{
${ }^{22}$ Other regressions that also include various combinations of the control variables from Table 3 yield essentially the same relationships.

${ }^{23}$ Unsurprisingly, given the problems referred to above regarding understatement of the sacking variable, these regression models are much better at identifying horses that change stables than those that do not. For example, if we use the estimated probability sample median as the cutoff point (that is, horses with an estimated probability of trainer sacking that is greater than the median of all estimated probabilities are predicted to change stables while all others are predicted to remain in the same stable), $64 \%$ of the trainer sackings are correctly categorized but only $51.3 \%$ of the non-sacked group.
} 
Table 7: Do Trainers Really Face Market Discipline? Horse Performance and the Propensity of Owners to 'Sack' Trainers

This table focuses on two sub-samples of client-owned horses that stayed in the same ownership throughout the season: (i) those that changed stables during the season ('sacked') and (ii) those that remained in the same stable throughout the season ('not sacked'). Panel A compares the mean (pre-sacking) performance of these two groups. Panel B estimates logit regressions where the dependent variable equals 1 if the horse was sacked and 0 otherwise. The performance ratio residuals are obtained from earlier regressions of horse performance on the control variables used in Table 3 (after converting 2002-03 monetary values to 1997-98 dollars). Panel C compares the pre- and post-sacking mean performance of the horses in sub-sample (i). In panels A and B, the sample size is 4000 , consisting of 354 horses whose trainers were sacked and 3646 that stayed in the same stable. In panel $\mathrm{C}$, horses that change stables more than once are excluded, leaving a total of 290 horses in the former group. Heteroskedasticity-robust standard errors are in parentheses. ${ }^{* * *}$ denotes significance at the $1 \%$ level.

\begin{tabular}{|c|c|c|c|}
\hline \multicolumn{4}{|c|}{ Panel A: Sacked and non-sacked horses - comparison of mean performance } \\
\hline & $\begin{array}{c}\text { Sacked } \\
(n=354)\end{array}$ & $\begin{array}{l}\text { Not Sacked } \\
(n=3646)\end{array}$ & Difference \\
\hline Consistency ratio & 0.094 & 0.163 & $\begin{array}{c}-0.069^{* * *} \\
(0.009)\end{array}$ \\
\hline Earnings ratio & 0.072 & 0.123 & $\begin{array}{c}-0.051^{* * *} \\
(0.007)\end{array}$ \\
\hline \multicolumn{4}{|c|}{ Panel B: Trainer sacking and unanticipated horse performance - logit regressions $(n=4000)$} \\
\hline Constant & $\begin{array}{c}-2.368^{* * *} \\
(0.058)\end{array}$ & $\begin{array}{c}-2.374^{* * *} \\
(0.059)\end{array}$ & \\
\hline Consistency ratio residual & $\begin{array}{c}-1.728^{* * *} \\
(0.399)\end{array}$ & & \\
\hline Earnings ratio residual & & $\begin{array}{c}-2.262^{* * *} \\
(0.588) \\
\end{array}$ & \\
\hline \multicolumn{4}{|c|}{ Panel C: Pre- and post-sacking — comparison of mean performance $(n=290)$} \\
\hline & Pre-sacking & Post-sacking & Difference \\
\hline Consistency ratio & 0.095 & 0.130 & $\begin{array}{c}-0.035^{* * *} \\
(0.013)\end{array}$ \\
\hline Earnings ratio & 0.073 & 0.102 & $\begin{array}{c}-0.029^{* * *} \\
(0.011)\end{array}$ \\
\hline
\end{tabular}


form strictly better following the change and average performance to rise. On the other hand, if stable changes are primarily the result of trainers determining that a horse has low ability and/or potential, then we would expect to see little change in horse performance following a stable change.

Panel C of Table 7 compares the mean performance of the horses that changed stables prior to the change with their mean performance following the change. To avoid an ad-hoc assignment to one group or another, we exclude horses that changed stables more than once during a season. This reduces the sample size, but otherwise has little effect on the results. For both performance measures, mean horse performance is more than $35 \%$ greater following the stable change, a difference that is significant at the $1 \%$ level. Thus, it seems unlikely that the results in panels A and B primarily reflect trainers sacking horses.

\section{Concluding remarks}

Although horse trainers have a direct financial incentive to devote more time, care and attention to horses that they own themselves, the average performance of these horses is inferior to that of horses they prepare for clients. This appears to reflect the fact that most horses are trained in large stables that have a lot to lose from upsetting clients: the performance premium of clientowned horses is positive in these stables, but is negative in stables where client satisfaction is less important. Overall, our results suggest that the market for horse training services is sufficiently transparent to motivate trainer effort in a way that is consistent with the interests of clients.

A possible objection to this conclusion concerns the role of trainer capital constraints in determining horse ownership. Perhaps client-owned horses are simply better than trainer-owned horses on average, due to the greater purchasing power of wealthy clients. If the latter then choose to place these horses in large stables — which seems plausible - then the positive impact of stable size on the performance of client-owned horses may have nothing to say about differential trainer effort. Against this, we offer three pieces of counter-evidence. First, we categorize trainer-owned horses as those in which the trainer has just some ownership share (which may be considerably less than 100\%), thereby minimizing the possible impact of financial constraints on trainer ownership. Second, our results are equally strong when the measure of client importance is the ratio of client- to trainer-owned horses in a stable rather than stable size per se. Third, it is by no means clear that outside clients should end up with the best horses: the greater knowledge and expertise of trainers mean that they have a significant advantage in obtaining at least a partial ownership share in the horses most likely to succeed. ${ }^{24}$ We also

\footnotetext{
${ }^{24} \mathrm{~A}$ fourth piece of evidence on this issue potentially comes from the sub-sample of horses that change from client- to trainer-ownership (or vice versa) during the course of a season. Within this sample, the group that stay
} 
show that the probability of trainer replacement by client owners is strictly increasing in horse under-performance, suggesting that the threat of sacking for trainers is a real one and that they do indeed face the right incentives. While any one part of our evidence could yield a different interpretation, together they form a coherent picture of trainers responding rationally to financial incentives in ways that resolve agency conflicts in most circumstances.

Our results contrast with those obtained for the real estate industry by Levitt and Syverson (2008) and Rutherford, Springer, and Yavas (2005). In those studies, real estate agents perform better when selling their own houses than when selling houses owned by clients. One difference between the two markets is that sales of agent-owned houses are only a tiny proportion of total sales, so the principal conflict of interest arises less often than in racehorse training. More importantly, real estate sales are typically one-shot deals offering little scope for repeat business with the same client, so there is relatively little to lose from exerting less-than-full effort on most occasions. This suggests that the situation faced by real estate agents is analogous to that of trainers with small stables and/or few outside clients.

By contrast, our findings are reminiscent of those obtained by Loderer and Martin (1997) and Himmelberg, Hubbard and Palia (1999), both of whom find no evidence of any relationship between managerial share ownership and firm performance, thereby casting doubt on the proposition that agency problems can be systematically reduced by requiring executives to hold more stock. Loderer and Martin suggest that one possible reason for this is that managers are effectively disciplined by product and labor market competition. Consistent with this view, our results imply that increasing a manager's ownership stake is only likely to be useful when future-income concerns are weak, for example when managers have become entrenched or are close to retirement.

However, important differences between racehorse trainers and corporate executives (and other more traditional asset managers) make it risky to push this analogy too far. One reason why horse trainers are likely to be particularly sensitive to client interests is the unregulated nature of the labor market in which they operate: horses can, and do, transfer from one stable to another literally overnight. Most labor markets do not work as efficiently as this, making future income far less dependent on current performance. In particular, the attractive termination packages frequently available to many CEOs mean that, at least in the short-term, their future income is considerably less risky than that of racehorse trainers. Instead, their situation in the same stable — which by definition cannot be beyond the trainer's financial reach — perform worse under client ownership, consistent with trainers exploiting their superior information about horse ability. But this effect is weaker in large stables and in stables with a large proportion of outside clients, thereby supporting our earlier results in a situation where trainer capital constraints are explicitly ruled out. However, the sample size is small and parameter estimates are marginally significant at best, so these results need to be viewed with caution. 
is most analogous to trainers who have little dependence on outside clients, suggesting that share ownership may well be an important bonding device for many. And although some other asset managers are potentially subject to similar discipline to trainers - it is usually simple enough to sack one's accountant or lawyer - performance is not always so easy to observe as at the racetrack. Nevertheless, our results provide some idea of what is possible in the right circumstances. Clearly, even seemingly opaque expert-service markets are capable of eliminating agency problems without the need to resort to formal regulation.

Finally, our analysis leaves some unresolved questions. First, why do some client-owners persist in using trainers who face weak incentives? We suspect that owners trade off the greater agency problems that arise in such stables against the more personalised - and sometimes cheaper - service that they are able to provide, and that for some owners the latter outweighs the former. Second, could the performance premium enjoyed by client-owned horses in stables with the right incentives be exploited by racetrack bettors? Although we have not investigated this issue, we are doubtful that any such strategy could be successful. Given the intensive scrutiny of track form by bettors, the information contained in ownership and stable type seems likely to be fully incorporated in race odds. Moreover, even if this were not the case, our results suggest only that profits are available over the course of a full season, exploitation of which would require deep pockets.

\section{References}

Agrawal, Anup and Mark A. Chen. 2008. Do Analyst Conflicts Matter? Evidence from Stock Recommendations. Journal of Law and Economics 51: 503-537.

Ainslie, Tom. 1970. Ainslie's Complete Guide to Harness Racing. New York: Simon and Schuster.

Asch, Peter, Burton G. Malkiel and Richard E. Quandt. 1982. Racetrack Betting and Informed Behavior. Journal of Financial Economics 10: 187-194.

Banerjee, Abhijit V. and Esther Duflo. 2000. Reputation Effects and the Limits of Contracting: A Study of the Indian Software Industry. Quarterly Journal of Economics 115: 989-1017.

Chen, Hsuan-Chi, and Jay R. Ritter. 2000. The Seven Percent Solution. Journal of Finance 55: $1105-1131$.

Fama, Eugene F. 1980. Agency Problems and the Theory of the Firm. Journal of Political Economy 88: 288-307. 
Fernie, Sue, and David Metcalf. 1999. It's Not What You Pay it's the Way that You Pay It and that's What Gets Results: Jockey's Pay and Performance. Labour 13: 385-411.

Gaffney, B., and E.P. Cunningham. 1988. Estimation of Genetic Trend in Racing Performance of Thoroughbred Horses. Nature 332: 722-724.

Gompers, Paul, and Josh Lerner. 1999. Conflict of Interest in the Issuance of Public Securities: Evidence from Venture Capital. Journal of Law and Economics 42: 1-28.

Grant, David. 2000. Two Over Three on Goodtime Sugar: The New Zealand TAB Turns 50. Wellington: Victoria University Press.

Hausch, Donald B., Victor S.Y. Lo, and William T. Ziemba. 1994. Efficiency of Racetrack Betting Markets. San Diego: Academic Press.

Henley Centre. 2004. A Report of Research on the Horse Industry in Great Britain. London: Defra Publications.

Himmelberg, Charles P., R. Glenn Hubbard, and Darius Palia. 1999. Understanding the Determinants of Managerial Ownership and the Link between Ownership and Performance. Journal of Financial Economics 53: 353-384.

Hsieh, Chang-Tai, and Enrico Moretti. 2003. Can Free Entry be Inefficient? Fixed Commissions and Social Waste in the Real Estate Industry. Journal of Political Economy 111: 1076-1119.

IER. 2004. Size and Scope of New Zealand Racing Industry: Economic Impacts and Community Social Benefit. Wellington: New Zealand Racing Board.

Jackson, Andrew R. 2005. Trade Generation, Reputation, and Sell-Side Analysts. Journal of Finance 60: 673-717.

Klein, Benjamin, and Keith B. Leffler. 1981. The Role of Market Forces in Assuring Contractual Performance. Journal of Political Economy 89: 615-641.

Levitt, Steven D., and Chad Syverson, 2008. Market Distortions When Agents Are Better Informed: The Value of Information in Real Estate Transactions. Review of Economics and Statistics 90: 599-611.

Loderer, Claudio, and Kenneth Martin. 1997. Executive Stock Ownership and Performance: Tracking Faint Traces. Journal of Financial Economics 45: 223-255. 
Ljungqvist, Alexander, Felicia Marston, Laura T. Starks, Kelsey D. Wei, and Hong Yan. 2007. Conflicts of Interest in Sell-Side Research and the Moderating Role of Institutional Investors. Journal of Financial Economics 85: 420-456.

Michaely, Roni, and Kent L. Womack. 1999. Conflict of Interest and the Credibility of Underwriter Analyst Recommendations. Review of Financial Studies 12: 653-686.

Michigan Harness. 2001. The Universal Driver Rating System or UDRS are used for Gauging the Success and Comparison of Harness Racing Drivers. http://www.mi-harness.net/trks/udrs.html (last updated May 13, 2001).

Puri, Manju. 1999. Commercial Banks as Underwriters: Implications for the Going Public Process. Journal of Financial Economics 54: 133-163.

Rutherford, R.C., T. M. Springer, and A. Yavas. 2005. Conflicts Between Principals and Agents: Evidence from Residential Brokerage. Journal of Financial Economics 76: 627-665.

Sauer, Raymond D. 1998. The Economics of Wagering Markets. Journal of Economic Literature 36: $2021-2064$.

Siegel, Paul D. 2002. How to Own Winning Standardbred Racehorses. USA: Russell Meerdink Company.

Telser, Lester G. 1980. A Theory of Self-Enforcing Agreements. Journal of Business 53: 27-44.

Tolich, Martin. 2002. Against the Odds: the TAB and the Sunset of the Horse-Racing Industry. In Gambling in New Zealand, edited by Bruce Curtis. Palmerston North: Dunmore Press.

United States Trotting Association. 2009. Report Description and Pricing Information. http://pathway.ustrotting.com/reportdescript.cfm

White, Halbert. 1980. A Heteroskedasticity-Consistent Covariance Matrix Estimator and a Direct Test for Heteroskedasticity. Econometrica 48: 431-460.

Williams, Joseph T. 1998. Agency and Brokerage of Real Assets in Competitive Equilibrium. Review of Financial Studies 11: 239-280.

Wilson, Alastair J., and Andrew Rambaut. 2008. Breeding Racehorses: What Price Good Genes? Biology Letters 4: 173-175. 